\title{
CDISC Clinical Classification Category Terminology
}

National Cancer Institute

\section{Source}

National Cancer Institute. CDISC Clinical Classification Category Terminology. NCI

Thesaurus. Code C118971.

Terminology associated with the clinical classification domain categories of the Clinical Data Interchange Standards Consortium (CDISC) Standard Data Tabulation Model (SDTM). 